Metal Processing. It appears that the authorities are taking steps to deprive him of his degree of Candidate of Technical Sciences, as a result of his desire to emigrate.

In the past, a few political prisoners and defectors have been similarly deprived. Earlier this year, Arkadii Tsinober of Riga contested the withholding of his doctor's degree on the ostensible grounds that his desire to emigrate made him "amoral and unpatriotic". However, Tsinober had defended his doctor's thesis in 1975, when the new regulations on higher degrees, although not yet in force, were well known to Soviet academic circles. According to these regulations, higher degrees may only be granted to "those who follow the norms of communist morality and those who act according to the principles of Soviet patriotism and proletarian internationalism". The regulations came into force in 1976 , and Tsinober might well be regarded as a victim of the changeover.

However, Borukhin received his candidate's degree in 1973, and if he is now deprived of it for his association with the Jewish emigration movement, it would imply that the authorities are prepared to apply the rule retroactively.

Vera Rich

\section{Microwaves may be damaging to health, says US report}

In what has been claimed as the first official recognition of the possible health hazards of microwave radiation, the General Accounting Office-the investigative agency of the US Congress -has concluded that the levels of such radiation to which the public may be exposed could be dangerous.

The GAO, in a report recently made public in Washington, also claimed that the Federal Government has been negligent in monitoring the problem. And Representative Elizabeth Holtzman (Dem.-Brooklyn) has called on President Carter and the Environmental Protection Agency to begin a research programme to determine safe environmental levels of microwave and radio-frequency radiation.

Mrs Holtzman has also asked the president to set up a nationwide monitoring system to determine the extent of actual public exposure, and to continue to maintain a White House office to coordinate the government's policy cn microwaves.

Although many scientists consider that present levels of microwave radiation present little public hazard, others claim that those exposed to levels far below the US government's existing standards have experienced symptoms that range from headaches and fatigue to decreased fertility and possibly genetic defects.
Back to nature

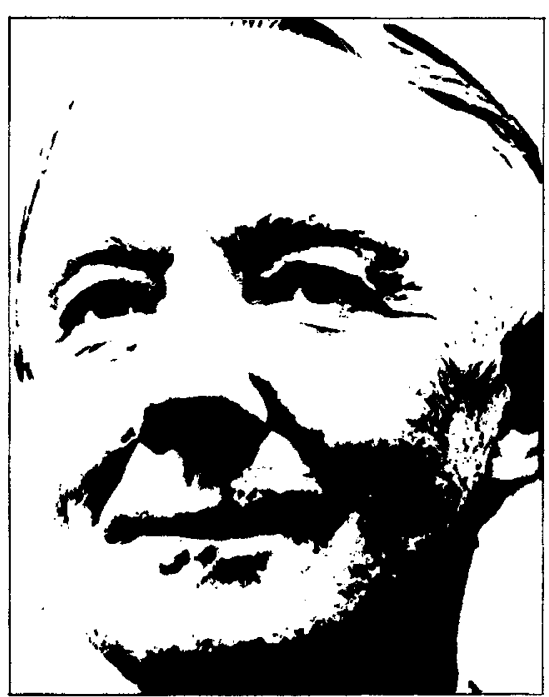

KENNETH MELLABY

Conservationists in Britain and the developed parts of Europe have learned the hard way that nature reserves require sophisticated management. If left alone, they may lose the wildlife for which they were originally scheduled. This is because so few areas are now covered with the natural, 'climax' vegetation, and because we have come to cherish plants and animals encouraged by the farming systems of our ancestors. Thus the attractive flowers of chalk downland only persist so long as the grass is grazed by sheep (or rabbits); otherwise there is an invasion of scrub and, finally, of forest. In some cases these forests resemble those which covered much of Europe three or more thousands of years ago, but in many areas introduced, exotic, trees such as sycamores or conifers from North America take over. The result of leaving an area to nature may be very different from that which existed before man was the dominant factor.

I expected to find things very different in Australia, when making an extensive tour of national parks, nature reserves, forests and farmland earlier this year. Australia, with an area of three million square miles, is sixty times as large as England and Wales, and has only a quarter as large a human population. Although the Aborigines have been there for tens of thousands of years, their numbers were small, and they kept no livestock and did no arable farming. Colonisation from Europe began less than 200 years ago, so agriculture has a very short history. It seemed reason- able to expect that the greater part of the vast area was still in its natural state, and that the best way to manage reserves would be to leave nature to take its course and to reduce human interference to a minimum.

In some desert and semi-desert areas this policy has generally been effective, but much of Australia has been so substantially modified by man that the results have been disappointing. Although the aborigines may not have practised farming of the conventional sort, they did a great deal of active land management. Large areas of the less-dry country were regularly and skilfully burned, something now described as fire-stick farming. Many indigenous plants flourished after cool, controlled burning, but the development of dense inflammable scrub was prevented, and a sward attractive to grazing kangaroos was produced. Early settlers described much of the landscape of Victoria and New South Wales as resembling "an English country gentleman's park" with large trees set at intervals in lawn-like grass. Little clearing was needed when cattle and sheep were brought in by the early graziers. Some areas have remained in this condition where cattle have cropped the herbage and controlled burning has continued. On the other hand where cattle and fire have been excluded following the declaration of National Parks or nature reserves, an almost impenetrable scrub layer has sometimes developed, with a greatly increased fire hazard. Such conditions, though welcomed by those who prize wilderness, may be far from favourable to many of the endangered species of indigenous wildlife.

Introductions of exotic plants and animals have complicated the situation. Although large kangaroos, which have no predators to control their numbers, may flourish on farmed areas, and may even become serious pests, not all marsupials are so adaptive, and able to compete with aggressive newcomers. Foxes, introduced by settlers nostalgic for the field sports left behind in Britain, and feral cats, escapees from outlying farms, may play havoc among the smaller animals which seem most at risk in the most 'natural' areas. Some attempts to encourage the regeneration of the natural vegetation on farm land absorbed into national parks has resulted in dense thickets of introduced blackberries and an animal population dominated by the exotic rabbit. In fact it appears that many of the conservation problems of Australia have much in common with those of Europe. 